\title{
A CONSTRUÇÃO DO DISCURSO SOBRE CIÊNCIA E SAÚDE EM PROGRAMA DA CBN
}

\author{
The construction of discourse about science and health in a CBN program
}

La construcción del discurso sobre la ciencia y salud en programa de la CBN

Bruno Sampaio Garrido

Doutor, Unesp

bgarrido@fc.unesp.br

Adriana Maria Donini

Mestre, Unesp

dridonini@yahoo.com.br

Jéssica de Cássia Rossi

Mestre, USC

jessicacrossi@yahoo.com.br

Alexandre Lopes

Especialista, Faculdade Eduvale alexandre.btu@bol.com.br

\section{Resumo}

Este artigo analisa a cobertura sobre doenças crônicas não transmissíveis no programa Saúde em Foco, da Rádio CBN. A investigação contemplou edições veiculadas entre 01/08/2013 e 20/10/2013 e verificou manifestações de heterogeneidade presentes no fio discursivo, à adequação dos conteúdos ao meio radiofônico e à divulgação científica e elementos constituídos pela enunciação. Para tanto, recorreu-se ao referencial teórico referente à semiótica greimasiana e à análise do discurso de linha francesa.

Palavras-chave: Rádio. Ciência. Saúde. Discurso. Enunciação.

\begin{abstract}
This article analyses the coverage about non-communicable chronic diseases in Health in Focus program, transmitted on $\mathrm{CBN}$ radio station. The investigation covered program editions, broadcasting between August $1^{\text {st }}, 2013$ and October $20^{\text {th }}, 2013$, and it verified heterogeneity demonstrations presented on discursive texture, the content fitting concerning to radio medium and science communication, and elements constituted by enunciation which allow building a corporeity (ethos and pathos). For that, it was resorted to the theoretical references concerning to the Greimas' Semiotics and the French Discourse Analysis.
\end{abstract}

Keywords: Radio. Science. Health. Discourse. Enunciation. 


\section{Resumen}

En este artículo se examina la cobertura de las enfermedades crónicas no transmisibles en la salud en el programa Saúde em Foco, la Radio CBN. La investigación incluyó temas difundidos entre 01/08/2013 y 20/10/2013 y manifestaciones de la heterogeneidad presente en el hilo discursivo, la adecuación del contenido a través de la radio y la científica difusión y elementos consistentes en la emisión. Para ello, se recurrió al marco teórico respecto la semiótica greimasiana y el análisis del discurso de la línea francesa.

Palabras-clave: Radio. Ciencia. Salud. Discurso. Enunciación.

\section{INTRODUÇÃO}

A alimentação inadequada e o sedentarismo têm contribuído para o aumento de doenças crônicas não transmissíveis (DCNT) como, por exemplo, obesidade, diabetes, hipertensão arterial sistêmica (HAS), problemas cardiovasculares, disfunções renais e hepáticas e alguns tipos de câncer.

A alta prevalência desses problemas de saúde fez com que eles ganhassem espaço nas pautas dos meios de comunicação. O boletim Saúde em Foco, veiculado pela Rádio CBN e apresentado pelo médico Luis Fernando Correia, é uma das produções que têm enfocado essa temática.

Neste artigo, inicialmente traçamos um panorama da incidência das DCNT, apresentamos as principais características do rádio, como o potencial do veículo pode ser explorado na divulgação de temas científicos e descrevemos elementos da Rádio CBN e da produção Saúde em Foco, objeto do nosso estudo. Em seguida, abordamos referencial teórico referente à semiótica greimasiana (cf. GREIMAS; COURTÉS, 2008) e à análise do discurso de linha francesa.

Nossa investigação contemplou edições do programa Saúde em foco veiculadas no período 01/08/2013 a 20/10/2013 e que abordaram doenças crônicas não transmissíveis. Além de verificar as leituras possíveis de um corpo comum de enunciados a partir de cada formação discursiva, empregamos recursos voltados ao estudo de mecanismos enunciativos, assim como elementos que se configuram como as instâncias mais concretas e superficiais na construção discursiva. Outros recursos analisados são as manifestações de heterogeneidade presentes no fio discursivo, à adequação dos conteúdos ao meio radiofônico e à divulgação científica e elementos constituídos pela enunciação que permitam construir uma corporeidade e, em particular, uma identidade própria tanto do eu (éthos) quanto do tu (páthos). 


\section{PANORAMA DAS DOENÇAS CRÔNICAS NÃO TRANSMISSÍVEIS}

Com as constantes mudanças na sociedade, decorrentes de fatores econômicos e sociais, ocorreram diversas transformações no cotidiano da população e que ocasionaram um ritmo de vida mais acelerado. Esse novo estilo, em alguns casos, teve como consequência a má alimentação, facilitada pelo consumo de refeições de preparo rápido e pelo sedentarismo, fatores que interferem na manutenção da saúde plena. (PASSARELI et al., 2004; MIRMIRAN et al., 2004).

Dessa maneira, nota-se um aumento de doenças crônicas não transmissíveis (DCNT) como a obesidade, diabetes, hipertensão arterial sistêmica (HAS), problemas cardiovasculares, disfunções renais e hepáticas e alguns tipos de câncer. Para se ter uma ideia, as DNCT respondem por mais de $58 \%$ das causas de morte no mundo, de acordo com a Organização Mundial da Saúde (OMS). No Brasil, esse índice chega a 60\%.

O agravo desses problemas de saúde podem desencadear outras patologias. No caso da HAS e do diabetes, eles estão diretamente relacionados ao aparecimento de acidente vascular cerebral (AVC), aterosclerose, doenças coronarianas, problemas circulatórios e cegueira, além de representarem potencial perigo de morte para seus portadores (RIBEIRO; ZANELLA, 2004).

Segundo o Ministério da Saúde, em 2006, foram diagnosticados no Brasil 21,6\% de hipertensos, índice que subiu para 23,3\%, em 2010. Ainda, aproximadamente cerca de 10 milhões de brasileiros são portadores de diabetes e, a cada dia, surgem 500 novos casos (BRASIL, 2011).

Com o crescimento dessas doenças, em 2012, inclusive, foi instituída uma rede de atenção a pessoas com DCNT dentro do Sistema Único de Saúde (SUS) com linhas de cuidados específicos voltados à prevenção e tratamento. $\mathrm{O}$ programa prevê o acompanhamento de pacientes por equipes multidisciplinares de profissionais da saúde. A OMS também publicou um projeto de planos de ação global para a prevenção e controle de doenças não transmissíveis para o período entre 2013 e 2020.

Considerando que as DNCT podem ser evitadas por meio da mudança de hábitos, diversas outras iniciativas governamentais e não governamentais e de educação formal e informal têm sido implementadas. Pela relevância que esses problemas de saúde citados e possíveis tentativas de revertê-los ou evitá-los adquiriram, o tema tem sido abordado de forma constante pelos meios de comunicação. 
PROGRAMA DE PÓS-GRADUAÇÃO EM COMUNICAÇÃO DA UNIVERSIDADE FEDERAL DE SANTA MARIA

\section{RÁDIO E SUAS POTENCIALIDADES NA DIVULGAÇÃO DE TEMAS SOBRE CIÊNCIA E SAÚDE}

Segundo levantamento do Kantar Ibope Media, que teve por base o primeiro trimestre de 2016, 89\% das pessoas residentes em 13 regiões metropolitanas escutam rádio, o que representa 52 milhões de ouvintes. (ABERT, 2016)

De acordo com a Pesquisa Brasileira de Mídia 2015 — hábitos de consumo de mídia pela população brasileira, encomendada pela Secretaria de Comunicação Social da Presidência da República (Secom) para compreender como o brasileiro se informa e que contou mais de 18 mil entrevistas, o meio rádio obteve o segundo lugar em audiência.

Estudo divulgado em 2012 pelo Instituto Ipsos Sensos, apontou que 74\% dos entrevistados disseram ouvir rádio frequentemente. $\mathrm{O}$ estudo, que envolveu 37 milhões de pessoas, revelou ainda que esse meio de comunicação é consumido em paralelo com outras atividades cotidianas como arrumar a casa, dirigir, se alimentar. Os dados desses levantamentos citados acima demonstram que esse meio continua tendo papel relevante no cenário nacional.

Esses dados demonstram que esse meio de comunicação continua tendo um papel relevante no cenário nacional se comparado a outras mídias, tendo em vista as audiências registradas.

O rádio possui algumas características peculiares que devem ser consideradas na elaboração de programas. A mobilidade, ampliada nos últimos anos com aparelhos de áudios portáteis e telefones celulares que possibilitam acesso a emissoras, é uma delas. Prado (1999) destaca como diferenciais do veículo a simultaneidade e a instantaneidade - que favorecem a primazia e a atualidade das informações levadas ao ar.

Durante muitos anos, a imaginação foi um atributo específico do rádio. Sobre esse aspecto, Reyzábal (1999, p. 217) observa que: "Qualquer uma das mensagens sonoras do rádio pode ser transformada, na mente de múltiplos ouvintes, em imagens elaboradas pelos próprios sujeitos, que lhes colocarão cores, cheiros e perfis desejados". Contudo, imagens utilizadas por algumas emissoras em seus sites têm provocado pequenas alterações relacionadas a esse fator, mas essa característica ainda é marcante no meio radiofônico.

A linguagem das mensagens veiculadas pelo rádio deve ser clara para facilitar a compreensão no momento em queos conteúdos são transmitidos. . Porém, esse aspecto e a heterogeneidade de público atribuída ao veículo não indicam superficialidade do conteúdo e da redação empregada. 
Ao produzir programas para o rádio deve-se elaborar roteiro que considere a estrutura do veículo e, durante a produção, explorar elementos que facilitem a compreensão e despertem o interesse pela informação. Portanto, a escolha de sons e o estilo de linguagem a ser utilizado favorecem a transmissão de mensagens e podem estimular o público a acompanhar as produções.

Em manuais de redação e livros sobre rádio também são comuns recomendações relativas à locução. O estabelecimento de uma tentativa de diálogo com o receptor é sempre destacado. Por exemplo, é aconselhável que se transmita a impressão de conversa com o ouvinte e não de leitura do texto apresentado.

Atualmente algumas emissoras têm disponibilizado em seus sites áudios veiculados possibilitando o acesso no momento que a pessoa interessada considerar mais adequado ouvir e, dessa forma, também se constrói a memória do veículo.

Sobre esse aspecto, Bufarah (2004) cita explicação de Trigo de Souza (2002, p. 94):

Outra característica da rede que altera a relação do usuário/ouvinte com o rádio é a capacidade de armazenamento de informações que possibilita uma individualização da comunicação de massa, embora os produtos sejam produzidos para audiências maiores.

A divulgação de inovações científicas e assuntos relacionados à saúde têm ganhado espaço nesse meio de comunicação nos últimos anos e o rádio é um veículo que favorece disseminação desses conteúdos, proporcionando informação e educação referentes a temáticas como essas.

Campos e Gomes da Silva (2013, p. 1) acreditam que: "Os programas radiofônicos para a divulgação científica podem agir como um agente provocador de reflexões e questionamentos, sendo esta prática um procedimento de crítica e conscientização social”.

Maia e Tonus (2010) destacam experiências mais recentes da divulgação científica no rádio:

Entretanto a discussão sobre a importância da ciência no rádio no Brasil começa a tomar vulto, haja vista iniciativas como a pesquisa realizada em projeto liderado pelo Ministério da Ciência e Tecnologia (MCT), pela Empresa Brasileira de Radiodifusão (Radiobrás), pelo Museu da Vida/COC/Fundação Oswaldo Cruz (Fiocruz) e pelo projeto "Science in Radio Broadcasting European" (Ciência na Radiodifusão Europeia) (SCIRAB) (MUSEU, 2009), bem como o Ouvir Ciência, incluído na Semana Nacional de Ciência e Tecnologia 2009, que tem como tema a Ciência no Brasil (SEMANA, 2009)

As fontes utilizadas, conhecimentos básicos das etapas envolvidas nas pesquisas e 
contextualização dos dados são elementos essenciais à divulgação científica.

Oliveira, Viana e Souza (2010, p. 3) consideram a credibilidade e a forma de apresentação dos dados elementos importantes na veiculação de informações por meio do rádio:

\begin{abstract}
Os dados científicos em rádio devem seguir às mesmas premissas das demais linguagens radiofônicas, sendo que neste caso a linguagem coloquial deverá evitar clichês, jargões, bem como expressões viciosas, sem, no entanto quebrar o objetivo pretendido: persuadir o ouvinte para a informação. Daí o cuidado com o desenvolvimento do texto. Tudo o que compõe o texto radiofônico deve ser previamente consultado, a fim de oferecer o máximo de crédito ao ouvinte. Neste sentido, as informações devem partir de fontes confiáveis, objetivando o mínimo possível de refutações, tanto por parte dos ouvintes como por parte dos concorrentes os quais tomarão as informações como verdades absolutas, por meio de recursos auditivos importantes, dentre eles a entonação. Ela, a entonação, é responsável tanto pela marca do locutor como pela viagem que o ouvinte faz ao o ouvir o rádio.
\end{abstract}

\title{
4 CBN E SAÚDE EM FOCO
}

A Rádio Central Brasileira de Notícias (CBN), criada em $1^{\circ}$ de outubro de 1991, é formada por uma rede de emissoras próprias (São Paulo, Rio de Janeiro, Brasília e Belo Horizonte) e afiliadas. Segundo a emissora, o seu jornalismo é "pautado pela informação correta, isenta, com espaço para a pluralidade de opiniões e a análise crítica do que está por detrás dos fatos".

Em São Paulo, a CBN opera na frequência 780 AM e, desde novembro de 1995, passou a transmitir também em 90,5 FM. A CBN diz adotar o formato "All News" que é utilizado quando uma emissora transmite, exclusivamente, notícias ou reportagens especiais. Seu slogan é "A rádio que toca notícia".

Estudo sobre a audiência das rádios AM e FM, em São Paulo, apontou quem na faixa AM a CBN ocupou a oitava posição de segunda à sexta-feira, no período de novembro de 2013 a janeiro de 2014. Na edição 2013 da pesquisa "Veículos Mais Admirados", encomendada pelo site e realizada pelo Grupo Troiano de Branding, a CBN obteve o primeiro lugar na categoria rádio. O estudo foi realizado com base no método conhecido por Índice de Prestígio de Marca (IPM).

Algumas emissoras têm optado por incluir nas suas programações especialistas em várias áreas que podem ser convidados de determinados programas ou terem um horário fixo na grade de programação. Na CBN há diversos comentaristas, entre eles, o médico Luís 
PROGRAMA DE PÓS-GRADUAÇÃO EM COMUNICAÇÃO DA UNIVERSIDADE FEDERAL DE SANTA MARIA

Fernando Correia, especialista em Clinica Médica e Terapia Intensiva, que comanda a produção Saúde em Foco, veiculada de segunda à sexta-feira às 10h35, com duração de, aproximadamente, dois minutos. Correia geralmente aborda os temas tendo por base resultados de estudos científicos e, no início do programa, tem utilizado uma linguagem que procura se aproximar do ouvinte.

Os áudios, depois de exibidos, permanecem no site da CBN e podem ser acessados a qualquer momento. Há a possibilidade de as pessoas assinarem o podcast e, dessa maneira, receberem as atualizações.

\section{ANÁLISE DO DISCURSO E DIVULGAÇÃO CIENTÍFICA}

Em primeiro lugar, vamos partir de uma premissa básica com a qual concordamos o fato de a linguagem ser um fenômeno dinâmico e entremeado por diversas idas e vindas, originárias de várias manifestações, entre diferentes dizeres constituídos ao longo da história e que, imbricados, formam uma tessitura.

Esse dinamismo se justifica pelo fato de todo ato de linguagem ser um mecanismo de interação de um eu com um tu, que pode se dar tanto de forma contratual quanto polêmica. Logo, corroborando um preceito crucial dos estudos de Bakhtin e Voloshinov (2006), é por meio da alteridade, dessas idas e vindas decorrentes das relações entre diferentes dizeres, que esses atos de linguagem se constituem - endossando, portanto, seu caráter dialógico.

A enunciação, segundo Benveniste (2005), não se limita a uma função operacional, mas visa estabelecer uma mediação entre as potencialidades da língua, pensadas como um sistema, e a sua atualização, no momento em que constroem os enunciados - configurando-se assim o seu uso. Esse papel mediador, estudado em profundidade por Fiorin (2005; 2013), diz respeito tanto às interações entre um eu enunciador e um tu enunciatário (que, juntos, formam o sujeito da enunciação) quanto à projeção, no fio discursivo, das categorias de pessoa, espaço e tempo referentes a cada uma dessas instâncias.

As projeções categóricas apresentadas por Fiorin $(2005 ; 2013)$ podem ser descritas da seguinte forma. Quando os objetos de referência forem as categorias de pessoa, de espaço e de tempo pertinentes à enunciação (eu-aqui-agora), e essas categorias são colocadas em discurso, temos um caso de debreagem enunciativa. Se o mesmo procedimento é empreendido, por sua vez, com as categorias de pessoa, de espaço e de tempo pertinentes ao enunciado (ele-láentão), ocorre a debreagem enunciva.

As manifestações mais comuns e ilustrativas desses fenômenos se dão justamente em 
textos que procuram ressaltar uma "objetividade", um efeito de distanciamento do enunciador em relação ao enunciado - usam-se, aqui, debreagens enuncivas - ou, ao contrário, busca-se evidenciar uma "subjetividade", uma marca de pessoalidade e identidade com discursos em particular - empregam-se, nesse caso, debreagens enunciativas (FIORIN, 2005; 2008; 2013).

Valendo-se de postulados do círculo de Bakhtin, Authier-Revuz (1990; 1998) debruçou-se em investigar esse contrato entre diversas formações discursivas que assumem, portanto, um caráter constitutivo, gerador de novos discursos. A heterogeneidade discursiva pode ser depreendida a partir do cotejo entre discursos emanados de diferentes formações discursivas ou a partir de indícios localizáveis no fio do discurso. As ocorrências das heterogeneidades mostradas marcadas, caracterizadas como áreas fronteiriças entre o discurso do um e o discurso do outro serão enfatizadas e aplicadas neste trabalho.

Da semântica global de Maingueneau (2008), marcadamente influenciada pela arqueologia foucaultiana, pelos trabalhos de Authier-Revuz sobre heterogeneidade discursiva e, de modo não evidente, do pensamento do Círculo de Bakhtin, aproveitaremos suas explanações acerca das formações discursivas, e de sua noção de interincompreensão regrada, decorrente das relações entre essas formações. Cada formação discursiva estrutura-se a partir de restrições semânticas, cujo papel é regular a leitura e a interpretação feita do outro - de outras formações.

Logo, quando se adota uma formação discursiva em particular, essas restrições semânticas constituem-se em formas específicas de se relacionar com esse outro e a partir daí se é criada uma imagem com o qual o enunciador interage. As diferenças interpretativas na maneira como cada enunciador interpreta o outro segundo a formação adotada acarretam no que Maingueneau (2008) designa como interincompreensão regrada, e cujo cerne é justamente a polêmica - pois é a partir dela que se geram outras leituras de mundo e formações discursivas (o que inclui também outras restrições semânticas) que agem de modo constitutivo e gerativo, assegurando-se o dinamismo da linguagem.

No que tange à divulgação científica, gênero discursivo no qual se enquadram os programas em estudo, corroboramos as afirmações de Zamboni (1997), Leibruder (2001) e Orlandi (2001), para as quais tal gênero é dotado de características próprias e estrutura-se a partir da reformulação do discurso científico, que lhe serve de fonte. Trata-se de um formato híbrido, que apresenta características dos discursos de saberes especializados assim como dos discursos informativos, de caráter referencial. Além disso, o discurso de divulgação científica tem por meta popularizar o discurso científico, viabilizando uma difusão mais abrangente dos conhecimentos e descobertas científicas mediante uma linguagem mais simplificada e 
acessível a um público mais vasto.

Oliveira (2002, p. 13) sintetiza com precisão as finalidades da divulgação científica:

A divulgação cientifica aproxima o cidadão comum dos benefícios que ele tem o direito de reivindicar para a melhoria do bem-estar social. Ela pode contribuir também para visão mais clara da realidade ao contrapor-se aos aspectos característicos de uma cultura pouco desenvolvida, ainda contaminada por superstições e crenças que impedem as pessoas de localizar com clareza as verdadeiras causas e os efeitos dos problemas que enfrentam na vida cotidiana.

Considerando os referenciais teórico-metodológicos expostos, centraremos agora nossa investigação nos programas selecionados para serem estudados nesse artigo.

\section{ANÁLISES DO PROGRAMA SAÚDE EM FOCO}

Nas análises de edições do programa Saúde em Foco veiculadas no período 01/08/2013 a 20/10/2013, além de verificar as leituras possíveis de um corpo comum de enunciados a partir de cada formação discursiva, empregaremos recursos voltados ao estudo de mecanismos enunciativos, ou, em outros termos, pertinentes à sintaxe discursiva, assim como as instâncias mais concretas e mais superficiais na construção discursiva, reveladas sobre a forma de temas e, especialmente, de figuras. Estas últimas colocam em discurso elementos que remetem a outros com existência concreta, presentes no mundo natural, como pessoas, coisas e lugares.

Outros recursos analisados são as manifestações de heterogeneidade presentes no fio discursivo, à adequação dos conteúdos ao meio radiofônico e à divulgação científica e, por fim, elementos constituídos pela enunciação que permitam construir uma corporeidade e, em particular, uma identidade própria tanto do eu (éthos) quanto do tu (páthos).

A princípio, trataremos dos elementos mais significativos na caracterização dessas formações discursivas (Formação Discursiva Científica - FDC; Formação Discursiva Educativa - FDE). Quanto à FDC, o dado mais significativo que a caracteriza (localizado em 13 dos 16 textos) é a sua proximidade com as comunicações científicas, voltadas para os cientistas. Pode-se ver que, nos textos citados, o enunciador-médico fundamenta suas explanações em pesquisas científicas (em sua maioria, internacionais) e, além de apresentar e comentar os resultados, traz detalhes dos procedimentos de pesquisa, explicando por exemplo a metodologia utilizada e a amostra pesquisada.

$\mathrm{O}$ aumento do número de diabéticos está ligado por sua vez também ao 
aumento do número de pessoas obesas ou acima do peso, especialmente no mundo ocidental. Para chegar ao resultado dessa pesquisa, os cientistas estudaram mais de 20 mil pessoas que, durante dez anos, eram avaliadas a cada dois. Os participantes eram filiados a um sistema de saúde que dá cobertura a funcionários públicos e professores da Coreia. Durante o estudo, foram coletados ali amostras de sangue para o teste de diabetes e dados sobre a dieta e o seu estilo de vida. Entre os tipos de câncer estudados, o diabetes está correlacionado, em homens, ao câncer de pâncreas; porém, foram significativas as correlações com câncer de esôfago, fígado e intestino. Nas mulheres, o diabetes aumenta principalmente o risco da ocorrência de tumores malignos do fígado. (SF3)

A utilização desses dados de pesquisa deu-se mediante o emprego do discurso indireto, em que o narrador "apropria-se" do discurso de um terceiro e o reformula, conferindo a este uma linearidade e uma regularidade - ou, nas palavras de Authier-Revuz (1998), trata-se de uma forma de "não coincidência do discurso consigo mesmo". Tal como no jornalismo regular, cuja matéria-prima origina-se de fontes externas (e que precisam ser marcadas de algum modo na tessitura discursiva), as comunicações científicas baseiam-se em estudos anteriores antes de se chegar a algum resultado inédito, ou mesmo a uma leitura nova de uma problemática já conhecida. Nessa forma de comunicação em particular, cujo principal expoente são os "papers", é preciso apresentar, ainda que minimamente, a problemática a ser trabalhada, os objetivos do estudo, o recorte teórico-epistemológico adotado, as metodologias e técnicas empregadas, resultados e discussões, além de aspectos conclusivos que podem orientar outros trabalhos e, ademais, detalhes sobre o corpus de pesquisa.

Assim, em ambos os casos, é preciso haver uma alteridade marcada no fio discursivo, um "ele" a quem o sujeito da enunciação precisa recorrer para fundamentar seu enunciado, para atender a determinadas coerções socioculturais ("não se faz ciência do nada") e, igualmente, fortalecer esse enunciado mediante um argumento de autoridade - as fontes seriam pesquisas realizadas em institutos reconhecidos pela comunidade acadêmica como confiáveis ou em periódicos científicos de prestígio. Para tanto, cabe aqui, além das formas marcadas e não marcadas de heterogeneidade - tal como o discurso indireto - o recurso à debreagem enunciva, isto é, à projeção das figuras do "ele" no enunciado, de modo a demarcar as fronteiras da alteridade - os limites entre um "eu" falante (enunciador-médico) e um "ele" a quem esse "eu" se refere (os cientistas autores das pesquisas citadas).

Por sua vez, no mesmo corpus, é possível detectar certos elementos concernentes à formação discursiva educativa (FDE), voltados a constituir uma interação mais duradoura entre enunciador e enunciatário com vistas a uma função mais formativa, portanto extensa. Um recurso frequente empregado pelo enunciador-médico é o da pergunta retórica, cujo papel 
não é obter uma resposta do enunciatário, mas exercer uma função fática, de prolongamento da interação da qual decorre o ato comunicacional em questão - seria, enfim, uma estratégia de "prender" a atenção do ouvinte para que este acompanhe o conteúdo do programa.

Café é bom pra saúde? Mas quanto? As dúvidas sobre os efeitos do consumo do café pra saúde deve dar assunto para uma boa conversa, ou até mesmo para se tomar um cafezinho. (SF2)

Nesse caso, faz-se presente a característica mencionada por nós em relação ao fato de ser recomendável em produções radiofônicas explorar recursos que tornem os enunciados mais atraentes. Notamos isso em algumas edições do programa como, por exemplo: "Hoje é sexta-feira e com certeza na 'happy hour' muita gente vai comer aquelas coisas gostosas, porém, muito gordurosas". (SF1)

Outros elementos característicos da FDE são as descrições metalinguísticas ou os operadores metadiscursivos (cf. MAINGUENEAU, 1997). No primeiro caso, o objetivo é decodificar a metalinguagem científica e empregar, no lugar desta, termos de uso corrente, compreensíveis para o público em geral. No segundo caso, ocorre uma reformulação do dito a partir de ajustes no registro usado no enunciado, substituindo um tom mais formal e técnico por outro mais coloquial. Esses aspectos também evidenciam a adequação do conteúdo veiculado ao meio radiofônico em virtude das peculiaridades do meio (como o fato de as pessoas ouvirem rádio enquanto exercem outras atividades) e da heterogeneidade do público, exigindo maior clareza e simplicidade na linguagem. É o que acontece, por exemplo, em SF15 e SF16, quando o enunciador trata o acidente vascular cerebral (AVC), tal como apresentado pela CID-10, por seu sinônimo mais usual - derrame.

Os acidentes vasculares cerebrais - ou derrames, como os leigos costumam chamar - podem ocorrer por conta de obstruções ao fluxo de sangue nas artérias do cérebro. (SF16)

No exemplo dado sobre o AVC/derrame, cabe uma observação. Apesar de a reformulação efetuada via metadiscurso agir para tornar o enunciado mais compreensível, é possível perceber um gesto de distanciamento do enunciador em relação ao termo coloquial. Esse gesto é também, como diz por Authier-Revuz (1998) uma "não coincidência entre o discurso consigo mesmo". Nesse caso, o enunciador apresenta dois modos de dizer a mesma coisa (AVC e derrame), mas identifica-se com apenas um deles - a nomenclatura médica. O outro no discurso é convocado para estabelecer assim uma relação contrastiva entre dois dizeres (ou polêmica, cf. MAINGUENEAU, 2008), entre duas formações discursivas distintas acerca de um fenômeno comum (e que resultam em dois ditos diferentes), sendo um deles 
escolhido para atender a uma finalidade na enunciação - embora não haja uma adesão do enunciador com esse dizer mais "simplificado".

A tentativa de maior clareza na linguagem recomendada ao redigir programas para o rádio, especialmente na divulgação científica, fica evidente nestes trechos:

Segundo uma pesquisa da Universidade de Yale, nos Estados Unidos, o segredo está numa conversa entre as células do intestino e o cérebro humano. (SF5)

Células musculares do coração cultivadas em laboratório são colocadas sobre um molde sintético e se juntam, formando como se fosse um remendo, para ser colocado e substituindo assim o pedaço do coração que foi danificado. (SF9)

Essa proteína é produzida num ritmo que segue o ciclo circadiano, que é o nosso relógio biológico, que funciona regulando, entre outras coisas, a atividade elétrica do coração. (SF8)

Além do colesterol LDL, o mau colesterol, que leva essa fama por conta de suas partículas menores capazes de como que entrar na parede das artérias e ficando ali e criar as placas de gordura que diminuem a passagem do sangue. E também existe o HDL, o colesterol bom, que talvez pudesse ter alguma coisa a mais por trás disso. (SF10)

Parece que os flavonoides, substâncias naturais presentes em certos vegetais e que têm características antioxidantes potentes. (SF12)

Em alguns momentos, o esclarecimento ao público de termos técnicos não ocorre de imediato, conforme notamos no SF em que o apresentador menciona que “(...) mulheres com níveis baixos de adiponectina no sangue antes da gravidez tenham risco aumentado de sofrer desse problema”. Apenas após a locução de mais um parágrafo é que ele retoma a palavra adiponectina para explicar o significado - embora, no mesmo programa, isso tenha ocorrido com mais clareza.

Ademais, também é possível perceber um tom menos descritivo-explicativo em alguns programas e verificar uma postura mais afável do enunciador, voltada ao aconselhamento, à orientação e à instrução (injuntivo). O objetivo aqui seria o de concluir o ciclo informativo do programa e induzir o ouvinte a uma mudança de comportamento acerca da própria saúde. Nesses casos, fica mais evidente a faceta de médico construída pelo enunciador a partir desse tom de aconselhamento; enquanto, na maioria dos casos - em virtude de um tom mais descritivo-explicativo -, é mais nítida uma ênfase aos papéis do enunciador na condição de especialista/cientista.

É importante frisar que tais injunções não se limitam ao paciente em potencial. Não é 
raro o enunciador-médico apresentar sugestões e recomendações voltadas ao poder público, sobre ações a serem tomadas nesse âmbito para que seja possível promover uma saúde de qualidade à população e salvar vidas em situações de emergência - como é o caso daqueles acometidos por AVCs.

Esse desafio [o tratamento do AVC] tem dois lados: o primeiro é o público que tem que ser informado dos sintomas típicos ou suspeitos e que se acostume a se levar essas pessoas o mais rápido possível para receber atendimento. Por outro lado, o sistema de saúde tem que [es]tar preparado pra receber essas pessoas, confirmar o diagnóstico e oferecer o tratamento ideal que pode, por exemplo, desobstruir uma artéria entupida ou estabelecer o melhor tratamento para as vítimas de um sangramento intracerebral. Nosso programa tem divulgado os sintomas típicos e o que você pode fazer para ajudar quem tiver esses sintomas. (SF15)

Também é uma característica importante para a constituição desse efeito de proximidade, embora pouco presente no corpus em geral, o recurso à debreagem enunciativa. Nesse caso, são projetadas nos enunciados as figuras pertinentes ao sujeito da enunciação até mesmo mediante o uso de "a gente", o que coloca enunciador e enunciatário em um mesmo patamar, incluídos em uma totalidade. Com isso, tem-se o efeito de conversa face a face entre o médico e seu paciente, construindo-se assim uma atmosfera mais acolhedora e propícia para os objetivos do programa, que não raro trata de assuntos nem sempre palatáveis para o público em geral. Tal atmosfera é composta também pelo uso (ainda que comedido) de uma linguagem mais informal, até com algumas brincadeiras (também empregadas de maneira moderada) feitas pelo enunciador-médico, tendo em vista uma maior descontração. Esse aspecto pode ser incluído na tentativa de o apresentador estabelecer um diálogo com o ouvinte. Conforme citados anteriormente, em rádio é aconselhável que se transmita a impressão de conversa com o ouvinte e não de leitura do texto apresentado.

O programa SF16 destaca-se dos demais por adotar um estilo estritamente injuntivo em sua totalidade. A preocupação do enunciador é apresentar informações acerca dos sintomas mais comuns do acidente vascular cerebral e os procedimentos a serem tomados caso o próprio ouvinte ou outra pessoa apresentarem um provável quadro da doença.

A aplicação desse remédio pode emitir (?) a desobstrução da artéria entupida e restaurar o fluxo de sangue ao cérebro. Vamos lembrar agora os principais sintomas que podem significar a instalação de um quadro de AVC. Se alguém apresentar os seguintes sinais deve ser encaminhado ao hospital para que determine se está ou não acontecendo o problema. Súbita dormência ou fraqueza da face, nos braços, nas pernas, especialmente se ocorrer de um lado só do corpo, confusão mental súbita, dificuldade na fala ou na compreensão de quem está falando, dificuldade pra caminhar, tonteira 
inexplicável ou perda de equilíbrio. Outro sinal importante pode ser uma dor de cabeça muito forte, de início súbito, sem causa conhecida e diferente de outras dores de cabeça que a pessoa já tenha sentido antes. Temos que lembrar que cada minuto conta. O tempo, nesses casos, é igual a cérebro que pode estar morrendo. Agora, um lembrete importante: esses sintomas podem surgir e desaparecer de forma espontânea. Isso também pode significar que existe um problema com a circulação cerebral e o risco de que um acidente vascular cerebral apareça nas próximas 24 horas é maior. Portanto, mesmo que os sintomas desapareçam, a pessoa deve ser encaminhada ao serviço médico. (SF16)

Há outro recurso, embora pouco utilizado, que também contribui para os efeitos acima - a embreagem. Segundo Fiorin (2005; 2013), esse recurso consiste em um retorno à instância da enunciação, a neutralizar as oposições das categorias de pessoa, de espaço e de tempo para, com isso, utilizar elementos de referência pertinentes aos sujeitos do discurso no lugar de outros. É o que ocorre, por exemplo, quando alguém, em uma situação comunicativa qualquer, refere-se a si mesmo na terceira pessoa do singular (o ele no lugar do eu), a fim de se criar um efeito discursivo em particular. O uso de "a gente" em SF7 dá-se de diferentes modos e ilustra os efeitos de sentido dos quais falamos.

No Brasil, a gente tá conseguindo resolver alguns problemas nas mulheres mais jovens, ou seja, melhorando as condições de saneamento, a adoção das vacinas, evitando a morte por doenças infecciosas, a melhora do cuidado da mulher na época de ter o filho, ou seja, no que a gente chama de mortalidade perinatal, ou seja, logo antes e depois do parto. Porém, isso traz também novos desafios. Essa mulher chega aos 50 anos e começa a morrer de quê? De doenças cardiovasculares, diabetes, hipertensão e também de câncer, colocando a gente como o mundo civilizado está, ou seja, o grande desafio do século XXI são as doenças não transmissíveis, chamadas de doenças crônicas para o público. (SF7)

No primeiro uso, o termo "a gente", equivalente ao "nós”, não exerce um papel puramente inclusivo, mas é utilizado no lugar de um "eles", ou melhor, aos agentes responsáveis pela saúde no Brasil - o poder público e os profissionais da área - mas também pode substituir um "ele", referindo-se ao próprio Brasil - e o "a gente" constrói uma relação metonímica, tomando o lugar de "a nação brasileira". O segundo, por sua vez, apesar de ser equivalente ao "nós", trata-se de um "nós" excludente, que não engloba o enunciatário (eu+eles). Isso porque ao dizer "a gente chama de mortalidade perinatal", o enunciador, pelo uso de um operador metadiscursivo, delimita as fronteiras do dizer e evoca, com isso, um sujeito constituído pelo enunciador (eu) e outros sujeitos com os quais se identifica e vinculados àquele dizer - esse "a gente" diz respeito, portanto, à comunidade médica, da qual pertence o enunciador e vincula-se ao emprego de um termo especializado (mortalidade perinatal) para designar um fenômeno conhecido pela população como "morte no período 
entre o início e o fim do parto".

É a partir dessas não coincidências que fica clara a contraposição (ou polêmica) entre as duas formações discursivas majoritárias no discurso da divulgação científica (MAINGUENEAU, 2008). Se, por um lado, temos uma FDE, seu foco será a simplificação das mensagens tendo em vista a sua captação por um número maior de pessoas e, como dissemos, sua finalidade é formativa, voltada a transmitir conhecimentos que exerçam um impacto durativo no cotidiano dos ouvintes. Por outro lado, a FDC identifica-se mais com a precisão, o uso das metalinguagens, das terminologias, com a finalidade de se constituir um arcabouço teórico a ser estudado e analisado por outros cientistas, a qualquer tempo e em qualquer lugar do mundo. Por seu acesso mais restrito, voltado à comunidade científica, o discurso vinculado à FDC volta-se para a intensidade, ao contrário da extensidade dos discursos educativos - de acesso mais amplo.

Com base nos elementos levantados anteriormente, há condições de se estabelecer duas figuras construídas pelo sujeito da enunciação mediante a interação entre o éthos do enunciador e o páthos do enunciatário. Segundo Fiorin (2008), trata-se de decorrências do contrato fiduciário estabelecido entre esses dois polos e que regulam os dizeres.

Vemos aqui a constituição de uma não coincidência entre duas formações discursivas distintas. Por um lado, vemos o discurso técnico-científico correspondente a uma área do conhecimento em particular (a medicina), demonstrada especialmente por um uso relativamente comedido de terminologias e de expressões pertinentes ao meio médico e, sobretudo, pelo esforço do enunciador em construir um distanciamento entre o seu dizer, ou o dizer da classe a qual representa, e o dizer do público em geral. Coloca-se aí um gesto que visa a marcar posição em prol do saber especializado e de seus respectivos profissionais, em contraposição ao senso comum do público leigo.

Contudo, também detectamos elementos mais afinados com uma FDE a partir do contrato que o enunciador estabelece com seu enunciatário e, desse modo, constitui uma interação entre ambos (cf. GREIMAS; COURTÉS, 2008). Se se busca uma proximidade com o discurso científico a partir de referências a estudos ou do recurso à terminologia especializada, também se visa a trazer o público em geral para esse cenário a partir de determinadas concessões. O exemplo mais nítido é o uso de um linguajar mais despojado e até mesmo informal, entremeado com os dados de pesquisas, ou outros momentos em que se percebe um tom mais formalizado. Outros recursos, como as perguntas retóricas e a redundância, reforçam o caráter fático e durativo dos enunciados, os quais se mostram 
concernentes com um propósito de ensinar algo ao enunciatário, em vez de apenas informá-lo.

Com isso, vemos que o enunciador do programa Saúde em Foco visa a construir uma imagem pertinente aos objetivos da produção, que é um éthos médico. Segundo essa imagem, cria-se uma figura que domina um saber especializado e metodologias próprias de trabalho. Entretanto, também é um profissional que lida com pessoas, e precisa estabelecer uma relação de confiança e de empatia com o seu enunciatário como um elemento crucial no próprio exercício do trabalho médico. Esse gesto de aproximação é, desse modo, obtido por uma mescla entre um posicionamento mais técnico-científico e outro mais próximo das relações cotidianas, do coloquialismo e do didatismo. Com o programa, assim como na relação médico-paciente, não há a preocupação apenas de se transmitir informações e despertar a curiosidade dos ouvintes, mas simular um ambiente agradável voltado para auxiliar as pessoas, a orientá-las a cuidar da própria saúde.

Definido o éthos, fica mais fácil construir o outro polo dessa interação - o páthos, a imagem do enunciatário presente na enunciação. Pelas próprias características demonstradas, que revelam um enunciador afinado com os saberes necessários para o exercício da profissão e fundamenta-se em pesquisas de fontes confiáveis para tal, vemos um enunciatário que dispõe de um repertório razoavelmente amplo para compreender traços da linguagem técnicocientífica empregada pelo enunciador. Logo, esse enunciatário "ideal" deve possuir um grau de escolaridade alto e, logo, pertencer minimamente à classe média para que, desse modo, consiga apreender mais adequadamente os conteúdos compreendidos - particularmente, em estabelecer relações entre os dados oriundos de pesquisas e os seus respectivos cotidianos. Portanto, percebemos que o páthos corresponde à imagem de um enunciatário minimamente letrado e com cultura geral suficiente para saber relacionar conteúdos diversos e aplicá-los a seus respectivos contextos.

Contudo, esses traços mais formais do éthos são mitigados pelo uso do coloquialismo, da ludicidade e de um tom mais propedêutico, voltado à instrução e à orientação - tal como os médicos fazem em contato com os seus pacientes. Com isso, mesmo que o enunciatário não consiga compreender aspectos da mensagem, a situação interacional permite um entendimento do assunto geral, tornando-o mais palatável e, portanto, apreensível por ouvintes com diferentes níveis de escolaridade e de diversas classes sociais. Ao adotar estrategicamente uma postura mais acolhedora, propícia a interações mais duradouras com um público mais amplo, o enunciador contrapõe-se a outra mais formal, que poderia ser compreendida como um sinal de arrogância. 


\section{CONSIDERAÇÕES FINAIS}

Na pós-modernidade, o ser humano tem à sua disposição uma série de recursos que tornam a sua vida mais fácil e dinâmica. Entretanto, essa comodidade tem levado as pessoas a se alimentarem mal e as tornado sedentárias. Tendo isso em vista, verificamos o crescimento de DCNT, que por esse motivo têm recebido a atenção da mídia, conforme observamos com o programa Saúde em Foco, da CBN.

Para entender como as DCNT foram abordadas pelo programa em questão, apontamos a situação delas no Brasil, o papel do rádio enquanto meio difusor de temas científicos e apresentamos algumas propriedades do Saúde em Foco. Após isso, expusemos as propriedades teóricas da análise do discurso e de que forma realizamos nossos estudos.

Em nossas análises do programa, realizadas de 01/08/2013 a 20/10/2013, foi possível identificarmos dois posicionamentos. O primeiro é de um discurso técnico-científico, referente ao conhecimento da medicina, que usa termos e expressões específicas do meio e, por isso, constrói um distanciamento entre o enunciador e o enunciatário. É um discurso que apresenta um posicionamento característico de um saber especializado. Já o segundo, referese ao discurso educativo por meio do uso de terminologias que se aproximam do público em geral. Podemos verificar isso no uso de uma linguagem despojada e informal, em perguntas retóricas e na redundância. Esses recursos são utilizados pelo enunciador para ensinar algo ao enunciatário, em vez de informá-lo.

Por essas características, vemos a construção da imagem de um enunciador (éthos) com um saber especializado (a medicina), mas que também tem habilidades interativas, as quais aproxima o médico das pessoas. Com essa mescla, o apresentador adapta-se às características do meio radiofônico e transmiti sua mensagem ao público do programa. A partir desse éthos, entendemos que o páthos, a imagem do enunciatário construída na enunciação, é a de um receptor alfabetizado e com conhecimento suficiente para relacionar conteúdos diversos e aplicá-los em seu cotidiano.

De maneira geral, o Saúde em Foco também reforça a possibilidade de se utilizar o rádio para aproximar a ciência do público em geral por meio da divulgação de informações recentes.

\section{REFERÊNCIAS}


PROGRAMA DE PÓS-GRADUAÇÃO EM COMUNICAÇÃO DA UNIVERSIDADE FEDERAL DE SANTA MARIA

ABERT - Associação Brasileira de Emissoras de Rádio e Televisão. Kantar Ibope Media aponta que $89 \%$ das pessoas escutam rádio em 13 regiões metropolitanas. Disponível em: <http://www.abert.org.br/web/index.php/clippingmenu/item/24983-kantar-ibope-mediaaponta-que-89-das-pessoas-escutam-radio-em-13-regioes-metropolitanas>. Acesso em: 15 jun. 2016.

AUTHIER-REVUZ, J. Heterogeneidade(s) enunciativa(s). Cadernos de Estudos Linguísticos, n. 19, p. 25-42, 1990.

Palavras incertas: as não coincidências do dizer. Campinas: Ed. Unicamp, 1998.

BAKHTIN, M.; VOLOSHINOV, V. Marxismo e filosofia da linguagem. 12. ed. São Paulo: Hucitec, 2006.

BRASIL. Ministério da Saúde: Dia Nacional de Combate e Prevenção à Hipertensão Arterial, 2011. Disponível em:

<http://portal.saude.gov.br/portal/saude/visualizar_texto.cfm?idtxt=36868\&janela=1>. Acesso em: 18 fev. 2014.

Secretaria de Comunicação Social da Presidência da República. Pesquisa brasileira de mídia 2015: hábitos de consumo de mídia pela população brasileira. Brasília: Secom, 2015.

BUFARAH JÚNIOR, A. Rádio na Internet: desafios e possibilidades. XXVII Congresso Brasileiro de Ciências da Comunicação, 27., 2004. Porto Alegre. Anais... Porto Alegre: Intercom, 2004.

CAMPOS, P. C.; GOMES DA SILVA, T. A divulgação da informação científica no rádio. Revista Alceu. Rio de Janeiro. v. 1. n. 26. Disponível em: <http://revistaalceu.com.pucrio.br/media/artigo14_26.pdf>. Acesso em: 25 out. 2013.

FIORIN, J. L. As astúcias da enunciação: as categorias de pessoa, espaço e tempo. 2. ed. São Paulo: Ática, 2005.

. Em busca do sentido: estudos discursivos: São Paulo. Contexto, 2008.

Elementos de análise do discurso. 15. ed. São Paulo: Contexto, 2013.

GREIMAS, A. J.; COURTÉS, J. Dicionário de semiótica. São Paulo: Contexto, 2008.

LEIBRUDER, A. P. O discurso de divulgação científica. In: BRANDÃO, H. H. N. (Org.).

Gêneros do discurso na escola. 2. ed. São Paulo: Cortez, 2001. p. 229-269.

MAINGUENEAU, D. Novas tendências em análise do discurso. 3. ed. Campinas: Pontes/Ed. Unicamp, 1997.

Gênese dos discursos. São Paulo: Parábola, 2008.

MAIA, M. R.; TÔNUS, M. Ciência e Tecnologia em rádios universitárias: as experiências de Ouro Preto e Uberlândia. In: FERRARETO, L. A.; KLÖCKNER, L. (Orgs.). E o rádio? Novos horizontes midiáticos. Porto Alegre: EdiPUCRS, 2010. 
MIRMIRAN, P. et al. Fruit and vegetable consumption and risk factors for cardiovascular disease. Metabolism, v. 58, n. 4, p.460-8, 2009.

OLIVEIRA, E. M.; VIANA, M. S.; SOUZA, S. A. Linguagem Radiofônica: o sistema de comunicação aplicado na divulgação científica no rádio. CONGRESSO BRASILEIRO DE CIÊNCIAS DA COMUNICAÇÃO, 33., 2010, Caxias do Sul. Anais... Caxias do Sul, UCS, 2010. Disponível em: <http://www.intercom.org.br/papers/nacionais/2010/resumos/R5-07061.pdf>. Acesso em: 27 fev. 2014.

OLIVEIRA, F. Jornalismo científico. São Paulo: Contexto, 2002.

ORLANDI, E. P. Divulgação científica e efeito leitor: uma política social urbana. In:

GUIMARÃES, E. (Org.). Produção e circulação de conhecimento: Estado, mídia, sociedade. Campinas: Pontes, 2001. p. 21-30.

PASSARELI JÚNIOR, O; BRANDÃO, A; FUCHS, F. D. Síndrome Metabólica. Rio de Janeiro: Diagraphic; Sociedade Brasileira de Cardiologia, Departamento de Hipertensão Arterial. 2004.

PRADO, E. Estrutura da informação radiofônica. São Paulo: Summus, 1989.

REYZÁBAL, V. A linguagem oral e sua didática. Bauru: EDUSC, 1999.

RIBEIRO F. F; ZANELLA M. T. Síndrome Metabólica e Diabetes Tipo 2. Sociedade Brasileira de Diabetes. 2004

ZAMBONI, L. M. S. Heterogeneidade e subjetividade no discurso da divulgação científica. 1997. Tese (Doutorado em Linguística) - Instituto de Estudos da Linguagem, Universidade Estadual de Campinas, Campinas.

\section{Original recebido em: 17/04/2014 Aceito para publicação em: 18/02/2016}

\section{Bruno Sampaio Garrido}

Graduado em Jornalismo pela Universidade Sagrado Coração, Mestre em Comunicação pela Unesp/Bauru, Doutor em Linguística e Língua Portuguesa pela Unesp/Araraquara. Assistente de Suporte Acadêmico do Departamento de Psicologia da Unesp/Bauru.

Adriana Maria Donini

Graduada em Jornalismo pela Universidade Sagrado Coração, Mestre em Comunicação pela Unesp/Bauru, Assessora de Comunicação e Imprensa do Instituto de Biociências da Unesp/Botucatu. 
PROGRAMA DE PÓS-GRADUAÇÃO EM COMUNICAÇÃO DA UNIVERSIDADE FEDERAL DE SANTA MARIA

Jéssica de Cássia Rossi

Graduada em Relações Públicas pela Unesp/Bauru, Mestre em Comunicação pela Unesp/Bauru, Doutoranda em Ciências Sociais pela Unesp/Marília. Docente do curso de Relações Públicas da Universidade Sagrado Coração.

Alexandre Lopes

Graduado em Enfermagem pela Universidade Paulista, Doutorando em Anestesiologia pela Unesp/Botucatu, Preceptor de Estágio em Graduação de Enfermagem em UTI e Pronto Socorro e Emergência pela Faculdade Marechal Rondon. Professor do Curso de Graduação em Enfermagem na Faculdade Eduvale de Avaré.

Esta obra está licenciada sob uma Licença Creative Commons 